Arab World English Journal (AWEJ) Volume 12. Number3 September 2021

Pp. $82-96$

DOI: https://dx.doi.org/10.24093/awej/vol12no3.6

\title{
Cross-cultural Language Learning: Interpretative Engagement
}

\author{
Anzhelika Solodka \\ Department of German Philology and Translation, Faculty of Philology, \\ V.O. Sukhomlynskyi National University of Mykolaiv,Ukraine \\ Corresponding Author: a.solodkaya1967@gmail.com
}

\section{Oksana Filatova}

Department of Social Studies and Humanities,

Admiral Makarov National University of Shipbuilding, Mykolaiv, Ukraine

\section{Oksana Hinkevych}

Department of Social Studies and Humanities,

Admiral Makarov National University of Shipbuilding, Mykolaiv, Ukraine

Oleksandr Spanatiy

Department of Department of Social Studies and Humanities

Admiral Makarov National University of Shipbuilding, Mykolaiv, Ukraine

Received: 7/6/2021

Accepted: 8/28/2021

Published: $9 / 24 / 2021$

\section{Abstract}

Conceptualization of foreign language teaching as a cross-cultural interaction means engaging learners in various cultural mediations. Language use becomes a form of interpretative architecture of a target language. Understanding language use from a discursive perspective develops meta-pragmatic awareness and interpretative capacities of learners. The study answers the question of how to design the architecture of context analysis. This research aims to determine the effective ways of interpretative engagement of learners with aspects of pragmatics in the Ukrainian university setting. The study investigates how the process of interaction shapes the engagement of learners in practices of noticing, reflection, and comparison of cross-cultural situations. The data came from a case study on cross-cultural language learning within the second semester, 2021. The study analyzes the audio-recording of the classes, researcher notes, and post-course interviews of 24 participants. This research used a method of the content analysis. The study of the results, based on six categories (narrative analysis, discourse analysis, semiotic analysis, interpretative analyses, conversation analysis, and critical analysis), showed that the learners started to consider the nature of their cross-cultural mediation. The research proved that through such an interpretative engagement, students become engaged into working with languages and cultures. The study presents some recommendations for language teachers to create a meaning-making process from multiple perspectives.

Keywords: cross-cultural context, cross-cultural language learning, interpretative engagement, interpretation of socio-cultural context, meta-pragmatic awareness, teacher scaffolding

Cite as: Solodka, A., Filatova, O., Hinkevych, O., \& Spanatiy, O. (2021). Cross-cultural Language Learning: Interpretative Engagement . Arab World English Journal, 12 (3) 82- 96.

DOI: https://dx.doi.org/10.24093/awej/vol12no3.6 


\section{Introduction}

Developing the ability to interact across cultures through the medium of a foreign language goes far beyond the acquisition of language skills. It includes recognition of diverse cultural norms and values, the ways to use the language, and interpretation of social actions.

Foreign language teaching shows some concerns about preparing learners for interacting with people with a wide range of cultural backgrounds, including but not limited to native speakers of the language (McConachy, 2018). It requires a reflective and analytical engagement to understand how culture shapes the meaning-making process in interaction.

The contribution of this study is to show the nature of the interpretative engagement of learners with aspects of cross-cultural pragmatics. This research aims to investigate how the process of cross-cultural interaction shapes the learners' attention in practices of noticing, reflection, and comparison. The study had the following target questions: What does it mean to learn and teach a language for cross-cultural communication? How to design classroom learning to prepare them for interacting with people with a variety of cultural backgrounds?

The research objectives of this study are as follows:

- Familiarize teachers and students with meta-pragmatic awareness through practices in learning activities;

- Determine the design meaning-making process from multiple perspectives;

- Explore possible solutions and recommendations for constructing meta-pragmatic awareness within classroom talk of more complex interpretations of pragmatic aspects of language in use and insight into the interpretative architecture of learners.

\section{Literature Review}

\section{Pragmatics and cross-cultural language teaching}

The process of Language learning is the development of the ability to meaningfully interpret and use features of a target language (Liddicoat \& Scrino, 2013). This interpretation is based on a wide range of assumptions about different cultures. It includes learners' development insight in the understanding of socio-cultural contexts and perceptions of cultural activities and identities.

Cultural contexts are the means of communication. They represent the content of the interaction, disclose the mechanism of learners' development insight across cultures and languages.

The concept of cultural context brings clarity to the understanding of the implementation of the cross-cultural interaction. It allows learners to determine the impact of cross-cultural interaction experiences on the process and results of gaining new cultural experience.

Verbitskyi (2004) has found that context is a system of internal and external factors, conditions, and behavior of human activity affecting the peculiarities of perception, understanding, and transformation of a particular situation. This system determines the meaning and significance of the situation and refers to the internal and external context. 
Internal context is a unique system to every human physiological and personality characteristics, conditions, guidelines, attitudes, knowledge, and experience; external context is a system of subject, socio-cultural, spatial, and temporal characteristics of action situations (Verbitskyi, 2004).

Thus, the internal (personal) context of the learner is seen as an image of the world built in interaction under the influence of different cultures (human, ethnic, national, etc.) and determines the individual values and sense perception, understanding, and transformation of a particular situation of interaction as a whole and its components.

Individual learners' contexts interpret socio-cultural contexts. The action of the internal context mechanism, aiming at developing world view, determines the meaning, sense of perception, and understanding of the world.

Zhukova (2005) considers the basis of this mechanism in the unity of the two processes of thinking: reflection and anticipation. Both techniques create conditions for the relationship between the external (socio-cultural) context and the learner's development insight.

According to Verbytskiyi (2004), the external socio-cultural context, stated by ideas of universal values, national, ethnic cultures, is the external condition that affects the formation of internal relationships between variables of individual consciousness of a learner.

Cross-cultural interaction space (the context) has a sense of creating an influence on the content and process of perception of new cultural models by IFL students in using the target language as a mediator. Preconditions for reflection and formation attitudes of a learner, causing a manifestation of social behavior and actions at the personal level, are formed within the crosscultural context (Solodka, 2015).

Learner's development insight, due to the influence of cross-cultural context, can be found at such levels that follow each other: the level of cultural sensitivity, the level of crosscultural competence, the level of subjectivity in the dialogue of cultures. 2015).

Consequently, penetration in a culture creates a personal meaning of perception (Solodka,

\section{Learners' Interpretative Engagement in a Cross-cultural Context}

Kim (2020) says that the essential task of teaching language is to help people participate in life. It goes beyond knowledge of the subject matter, and it goes beyond any simple type of well-being. Language learning can immerse students in others' worlds, and it can foster empathy and understanding across social and political divides. But it can do so only if we base our research and pedagogy on an adequate account of language and culture.

Learners should understand how language works as a tool of communication. It includes the basis for initial interpretative work. Focusing on language as discourse brings learners closer to constructing the meaning according to their communicative intentions (Haugh, 2010). This process activates their meta-pragmatic knowledge for interpretation of language as a social act 
(Lo Castro, 2003). The interpretation of cultural contexts implicates the structuring of pragmatic actions. It helps learners consider how the meaning works (Goodwin \& Duranti, 1992) and understand how speakers construct the meaning, interpret and evaluate contributions to talk (Kasper \& Rose, 2001). This activity demands more engagement of students' interpretative abilities, which leads to reflective and analytic learning when students reflect on their cultural knowledge and experience to make sense of the language they encounter (Kearney, 2016).

McConachy (2013) thinks that classroom talk provides a context in which learner interpretations are articulate. Articulation is instrumental in making the learners' ideas available for future reflection, gradually revealing the aspects of interpretative architecture through which interpretations are operating. It helps students to account for pragmatic appropriateness and manifest socio-cultural variables (Meier, 2015). This process creates an individual learning recourse of students and brings it to awareness. Students' interpretations of themselves become a tool for collaborative learning (McConachy, 2013).

Teachers encourage the learners to think about how to use the language according to the context when comparing norms across languages and cultures and consider alternative interpretations concerning L2 and L1 (Liddicot \& Scarino, 2013).

According to McConachy (2018), experience talk is constructed through interaction among learners within the classroom, generates descriptive, evaluative, and explanatory accounts of experience that create learning opportunities. In this case, the experience acquires features of a text (who said what, in what order, and why) - experience talk functions as a resource for learning within the reflection on L1 and individual experience of learners. Effective teacher scaffolding generates collaborative thinking among learners, meta-pragmatic awareness through developing insight into a cultural basis of meta-pragmatic judgments.

Crozet (1996) admits that classroom performance activities such as role-plays, combined with post-performance reflection, create affordance for practicing intercultural mediation. The classroom provides an important cross-cultural environment (context) in which learners can try out different ways of interacting and, through reflection, explore the meanings and intentions they can realize through the target language resources available to them (McConachy, 2018). Cross-cultural consideration and comparison generate the ability to communicate in the target language. Such insights provide a tool for learners to reflect more closely on the nature of their language use and the meanings and impressions they wish to construct (McConachy, 2018)

\section{Aspects of Teacher Scaffolding}

The learners do not always notice the aspects of the language or emotional reactions when they attempt to communicate. Reflection leads learners to see the elements of their knowledge and consider them in a new light. The interpretation of them transforms into metapragmatic awareness (Houghton, 2012). Learners use reflection to specify the nature of their emotional reactions concerning particular features of L1 and L2. It helps to understand the importance of meta-linguistic awareness within language learning as a matter of knowledge, a form of understanding within the cognitive and practical domains of linguistic interpretation (McConachy, 2018). 
Language makes individuals' perspectives on the language, and culture available to others, and others' reactions scaffold future reflection on the articulated perspective (Liddicoat, 2014, Swan \& Lapkin, 2010).

The discussion of the intercultural learning practices focuses on how the interpretative process works for learning and the perspective of cross-cultural competence. The teacher scaffolds the students' abilities to draw on existing knowledge to engage cross-cultural learning practices in context and increasingly develop knowledge, insight, and sensitivity for crosscultural interactions (McCornahy \& Liddicoat, 2016).

The teacher's primary role in implementing intercultural language teaching is to help learners interpret the linguistic and cultural representations drawn from different souses (Baker, 2015). Teachers create scaffolding discussions and encourage learners to generate their instructional strategies for communication (Solodka, Zaskaleta, \& Moroz, 2021).

Chou and Chen (2008), Kumi-Yeboah (2018) prove that instructional strategies facilitate designing cross-cultural collaborative learning (group work, self-introductions, and cultural awareness activity, computer-supported collaborative learning activity).

Scaffolding includes: supporting reflective understanding of learners by making active use their knowledge; introduction of meta-pragmatic concepts in details in real contexts avoiding generalizations (van Compernolle, 2014); usage of students' L1 for checking understanding when students use L2 images to develop a toolkit (Cook, 2010), contrasting culture-specific concepts used for meta-pragmatic judgments (what is (in)appropriate, for instance) (Liddicoat \& Scorino, 2013); learners' elaboration on their interpretation of language and culture (Donato, 1994) allowing all voices to be heard (Byram, 1997; Houghton, 2012); providing the inherent variability associated with language use (van Compernolle, 2014); presenting a perspective on language use as one reference point for developing learners' meta-pragmatic awareness (McConachy, 2013); contributing teacher's meta-pragmatic awareness as a resource for the emerging analysis (Scarino, \& Liddicoat, 2016) though meta pragmatic talk, to make the tools used for intercultural work more salient for learners (McConachy, 2018).

\section{Usage of L1 for Facilitating Understanding of L2}

Learners' existing interpretative architecture in L1 reflects on the interactional experience in learning L2. Learners add new language and socio-cultural knowledge modifying and reorganizing existing knowledge (Kecskes, 2014). Reflection on a cross-cultural experience in students' L1 has an essential impact on developing an intercultural perspective on language use. It mobilizes their interactional experiences as a way of illustrating, justifying, and challenging normative ideas about L1 use, as well as considering how assumptions and experiences drawn from the L1 may influence perceptions of L2 pragmatics (Pizziconi, 2009; McConachy, 2018). Learners develop the awareness of the general contextual contingency of linguistic actions and the subtle norms and assumptions that pervade everyday sense-making. Using L1 creates a context for discovering similarities and differences of L1 and L2 evaluating interaction in collaborative analysis. Teachers use scaffolding strategies to avoid generalization and stereotyping. 
Using L1 in teacher scaffolding creates potential communal learning recourse as a reference point for reflecting on their knowledge (McConachy, 2013). Interpretations of contextual interactions using L1 constitute meta-pragmatic awareness of each participant and understanding insight constructions "how language works to make the world meaningful" (Phipps \& Gonzalez, 2005). L1 mediate understanding of the linguistically constructed social world within the process of learning L2.

\section{The development of Meta-pragmatic Awareness within and across Classroom Interaction}

The language classroom is not a place where learners develop language skills. Students work with the target language developing interpretative abilities. This process depends on how teachers conceptualize the language as the code and culture as language-external products (Liddicoat \& Scarino, 2013) to overcome fundamental barriers to intercultural language teaching (Diaz \& Dasli, 2017; Kearney, 2016). It helps to conceptualize 'language' in terms of 'language use' as a form of cultural behavior (McCornachy \& Liddicoat, 2016). Dealing with pragmatic phenomena demands teacher professional development for intercultural language teaching. Teachers scaffolding learning provides the model of intercultural interaction for learners. Student's engagement in interpretative activities actualizes their experience of using the language. Teachers articulate their perspectives, make cultural comparisons and justify judgments. Studies on interlanguage pragmatics can be helpful for teachers to develop an awareness of variation in language learner's patterns of L2 language use and determination of appropriateness (Ishihara \& Cohen, 2010).

Language use means changing the view of language as a rule-governed system into considering it as a form of culturally variable behavior. Accounting cultural relativity of pragmatic norms mediates various understanding of the linguistically constructed social world within language learning. An interpretative engagement with language use represents a threat to cherished notions of stability, normality, and traditional views on authenticity in language teaching (van Lier, 1996).

\section{Cross-cultural Learning Practices in Classroom Interaction}

The development of cross-cultural perspectives demands a consistent interpretative engagement of language use and meta-pragmatic awareness. According to Linddicoat and Scarino (2013), intercultural language learning includes interacting, noticing, comparing, and reflecting on aspects of the language culture. Learners should have various communication samples and opportunities for discussion and trying out new expressions, new speech acts, and new tasks. Learning occurs as learners engage with a range of linguistic input. Noticing develops awareness of the target language (vocabulary, rhetorical patterns, norms of interaction, etc.). It creates an understanding of linguistic regulations and potential across languages. Comparing means reconciliation and explanation what learners noticed about target language concerning L2 knowledge and other languages. Reflecting involves learners in the process of considering the meaning that includes particular ways of viewing the world. It encompasses a cognitive and affective dimension. Interacting supports all these processes. It highlights discursive stratagies in performance tasks and languaging - talk in which language becomes the object of discussion. Languaging occurs as an individual and collaborating classroom activity. It serves to express learners' perspectives on the exposed material and helps them develop insight into their thoughts. Teachers scaffold the collaborative development of insightful interpretations into aspects of 
language and culture. This process means that learners relate to input about target language pragmatics. They reflect what they have encountered and compare aspects of interaction across cultures. Through this process, learners develop sensitivity to the contingency of meaning across languages and cultures and explore the cultural assumptions that influence constructing sense, perception of the world, and expectations regarding language use in context. The following meta-pragmatic commentaries are helpful in the classroom: commenting on the language use, requesting clarification of meaning, explaining meanings, criticizing ways of using language (Vershueren, 2004). Such activities specify learners' expectations regarding linguistic implications in a particular interpersonal context and provide a link between explicit talk about the language and the development of meta-pragmatic awareness. Learners become analytical and reflective users of L2. They can develop their capacities of interpretation of cross-cultural context through experience in interaction. The teacher plays a crucial role as a language mediator in facilitating meaningful engagement in the learning practices.

\section{Methodology}

This research established two specific goals: to develop an awareness of cultural knowledge and assumptions in the interpretation and evaluation of language use and to develop learners' interpretations and perspectives. To achieve the goals of the study, researchers used factual materials. Usage of authentic situations opens up the possibility for meaningful engagement and learning and allowes learners to reflect on the significance of language encounters. The authenticity derives from the nature of the interpretative engagement with language and how learners can use the language in analytical methods, reflecting and exploring new cultural meanings. The involvement of students in cross-cultural situations aims to promote the active construction of meanings across languages and cultures. Explicit discussion requires reference to target and native language. The study utilized the following multiple methods for data collection: audio-recording of the classes, researcher notes, and post-course interviews.

\section{Participants}

The researchers conducted the study at the Master's level for English language learners in the Faculty of Philology, V.O. Sukhomlynskyi National University of Mykolaiv, and in the Department of Social Studies and Humanities of the Admiral Makarov National University of Shipbuilding Ukraine. There were 24 Master level students in the study, aged between 22 and 24. The study was conducted in the second semester (2021).

\section{Research Instruments}

The researchers used content analysis in this study. According to Neuendorf (2002), content analysis we can understand as a careful, detailed, systematic examination and interpretation of a particular body of material to identify patterns, biases, and meanings. The content analysis included narrative analysis, discourse analysis, semiotic analysis, interpretative analyses, conversation analysis, and critical analysis (Neuendorf, 2002).

Narrative analysis is a basic form of communication and universal mode of verbal expression. Via narrative analysis, the teacher can assess individual experience in-context communication. This technique involves a description of formal narrative structure. Attention focuses on difficulties of communication, choices, conflicts, complications, and developments. The analysis involves the reconstruction of the composition of the narrative. 
Discourse analysis concentrates on communicator motives, the characteristics of meaning concerning cross-cultural interaction.

Semiotic analysis meets deep meanings of massage. It aims at discovering deep structures, latent meanings, and the signifying process through signs, codes, and binary oppositions. The assumption is that the student is a competent member of the culture. The semiotic analysis aims to identify linguistic structures that organize relationships between sins in communications in a communicative process.

Interpretative analysis focuses on the formation of understanding the context. It involves theoretical sampling, analytical categories, comparative analysis, and the formulation of types or conceptual categories.

Conversation analysis is a technique for analyzing naturally occurring conversation. It characterizes the involvement of the speaker in communication.

The critical analysis identifies understanding of social and cultural differences. The critical analysis gives summative statements that bring the details into line with cultural frameworks. categories.

According to content analysis of Neuendorf (2002), the researchers created coding Table 1. Coding categories

\begin{tabular}{|c|l|l|l|}
\hline № & \multicolumn{1}{|c|}{ CATEGORY } & \multicolumn{1}{c|}{ GOAL } & CODE \\
\hline 1 & Narrative analysis & To understand relationships between a text and reality. & NA \\
\hline 2 & Discourse analysis & $\begin{array}{l}\text { To find the characteristics of language manifestation and } \\
\text { word use. }\end{array}$ & DA \\
\hline 3 & Semiotic analysis & To identify rules of language and culture. & SA \\
\hline 4 & Interpretative analyses & To understand the coding massages & IA \\
\hline 5 & Conversation analysis & $\begin{array}{l}\text { To describe the way how ordinary speakers use and rely on } \\
\text { conversational skills and strategies. }\end{array}$ & CA \\
\hline 6 & Critical analysis & To understand social and cultural differences. & CRA \\
\hline
\end{tabular}

These categories constituted the lens for analyses of the lessons, researcher notes, and interview data.

Table 2. A sample of the interview "Language input: Requesting"

\begin{tabular}{|l|l|l|}
\hline № & \multicolumn{1}{|c|}{ ITEM } & \multicolumn{1}{|c|}{ CODE } \\
\hline 1 & How to make a request? & NA \\
\hline 2 & What could you tell about requests as important socio-cultural variables? & CRA \\
\hline 3 & How is a request linked to the judgment of (im)politeness? & CA \\
\hline 4 & How to interpret a request regarding size and timing? & CA \\
\hline 5 & How to make the request sound "kind"? & DA \\
\hline 6 & How is the use of paralinguistic tired up with the intention of the speaker? & DA, SA \\
\hline 7 & What should be linguistic choices from a strategic perspective? & DA \\
\hline 8 & $\begin{array}{l}\text { Comment the following statement: Culturally derived assumptions about rights and } \\
\text { obligations in a workplace context should be a matter of referencing in requesting. }\end{array}$ & $\begin{array}{l}\text { NA, CRA, } \\
\text { CA }\end{array}$ \\
\hline 9 & Could you provide your strategy of initiation-response-feedback in requesting? & CA \\
\hline 10 & How to make the indirect requests? & DA, IA \\
\hline
\end{tabular}


Arab World English Journal (AWEJ) Volume 12. Number 3. September 2021

\begin{tabular}{|l|l|l|}
\hline 11 & What should be the sentence structure to highlight the issue? & DA \\
\hline 12 & Could you relate sequences of talk to broader interactional goals? & CA, IA \\
\hline 13 & How to analyze the requesting behavior within cultural frames? & CRA \\
\hline 14 & $\begin{array}{l}\text { What requesting behavior may be preferred from the perspective of English } \\
\text { pragmatic norms? }\end{array}$ & DA, SA, CRA \\
\hline 15 & What is the way to accommodate cultural norms? & CA, CRA \\
\hline 16 & What can be your outcome of intercultural mediation? & $\begin{array}{l}\text { NA, DA, SA, IA, } \\
\text { CA, CRA }\end{array}$ \\
\hline
\end{tabular}

\section{Research Procedures}

The data came from a case study on intercultural language learning in 'Theory and practice of cross-cultural communication.' This course constituted four hours of classroom-based learning per week (30 hours overall). It had two aims: 1) to develop students' communicative abilities in four skills to an 'advanced' level; 2) to impart valuable cultural knowledge for daily life when studying abroad.

\section{Results}

\section{The construction of context analysis}

The analyses of cross-cultural situations show a range of analytical foci constructed within the classroom discussion and how processes of reflection, noticing, and comparison supports the development of meta-pragmatic awareness.

The teacher engages participants in a discussion of the context situation. The students explore the potential significance of language choice within unfolding interaction. Contextual analysis requires not so much a 'matching' of language forms to context, but a relating of language forms to context. Such a process mobilizes the interpretative architecture on learners and provides a route to closer reflection on the learners' assumptions about language use in context (Meier, 2010).

Language learners need to gradually develop a view of language as a dynamic resource that the speaker uses for social interaction. Learners collaboratively reflect on motivations behind linguistic choices, both concerning individual statements and sequences of utterances. Such reflection generates an analytical frame. Learners begin to examine how the speaker strategically encodes social intentions. Through analysis and review within classroom interaction, learners start to attend to language strategies.

The researchers provide examples of how to design interpretative engagement. Students studied complimenting within the theme 'Language use as a tool for relationship management.' Teachers chose complimenting for the discussion to show students that these speech acts can have sever implications for making and breaking interpersonal relationships (Solodka \& Perea, 2018; Solodka, A., Perea, L. \& Romanchuk, 2019).

The base for discussion was the following situation: Thomas is a supervisor of Kate in a small IT company. This conversation occurs in the office.

Thomas: Hi. Wow, have you lost weight?

Kate: Oh, um. I'm not sure... probably not.

Thomas: Oh no. You look great! 
Kate: Oh. By the way, I have finished checking the documents.

The construction of context analysis includes some stages: interpreting intentions, exploring constraints on speaker choices in interaction, scaffolding the building of justifications for judgments, contextual modification for deepening reflective analysis (McConachy, 2018).

\section{Stage 1: Interpreting Intentions behind Complementing}

Analytical scaffolding work from the teacher helped to approach the discussion of this dialogue through linguistic focus. The initial analytical focus was on the perceived feelings and communicative intentions of the situation characters. This situation engaged learners in multilayered interpretative processes. Students gave the following comments: 'Thomas is attracting Kate,' 'Comments about weight is so personal,' 'It is inappropriate behavior of supervisor to greet their employee in such way.'

\section{Stage 2: Exploring Constraints on Speaker Choices in Interaction}

This stage of analysis was to view the roles of participants in interaction and exchange their ideas about what should say and should not say within these roles. Students commented on the situation from hierarchy frame: 'Superior status of Thomas in the workplace is a reason for negatively evaluating his question about Kate's weight,' 'Kate wanted to divert attention away from her physical appearance,' 'She was unable to accept the compliment and unable to strongly reject it because of subordinate status,' 'Kate feels discomfort and expresses it in her reactions.'

The students explore the feelings and intentions of the situation characters and consider how workplace hierarchical structures may have influenced Kate's strategic use of language in expressing her discomfort. They viewed the interaction from the perspective of each speaker and then considered the implications of unrecognized intentions of conflicting frames of interpretation in exchange.

\section{Stage 3: Scaffolding the Construction of Justifications for Judgments}

This discussion stage was to push learners to consider the impact of contextual factors on the interactional features observed in the dialogue. Students built initial evaluations as to whether the compliment in question could be appropriate or not. The teacher used various scaffolding strategies to depth the impact of contextual factors on interactional features. For example, the teacher launched the discussion to consider that Kate and Thomas had been colleagues for a long time. In responses of the participants, there was an understanding that compliments in English usually attract a reply, such as thanking behavior when accepted. It was the focus on the reaction of Kate. In other words, students are not only looking at the relationship between utterances and the context, they directly explicit attention to the co-text of a particular utterance (Lo Casto, 2003). This discourse perspective on utterance constitutes a framework for the construction of a more nuanced interpretation. The teacher scaffolds the analysis by presenting potentially relevant variables for consideration by elaborating of students' viewpoints to re-evaluate their research. In the construction of this strategy, the students do scaffolding work for each other. This example illustrates that peer scaffolding in the meta-pragmatic study is constituted not only by the content of students' interpretations but by the particular forms and strategies through the articulated content. This kind of analytical discussion provides a context for utilizing meditational tools to develop the students' abilities as effective analyzers of language and culture (Linddicoat \& Scarino, 2013). 


\section{Stage 4: Contextual Modification for Deepening Reflective Analysis}

Learners draw connections between observed features of language use and the aspects of context which they believe are relevant to shaping interactional decisions. The teacher asked the students to consider the potentially differing implications of the language used in the situation. This example explored two social dimensions - gender and hierarchy. The teacher proposes the new scenario: 1) to change the place of Thomas and Kate; 2) to change the country where the situation takes place.

The teacher takes explicit questioning strategies which encourage the students to consider the possible application of their generalization to make culturally derived assumptions. In this classroom discussion, the hypothetical modification to the scenario functions as an effective catalyst for probing assumptions relating to the meta-pragmatic frames (gender and hierarchy in cross-cultural aspect) activated for interpretation and evaluation of the language use contained within. Students justified their ideas and started to become more explicitly aware of some cultural assumptions, which underlie their variations of the cross-cultural situation.

The post-course interview data provided the comments of students, which showed their progress related to cross-cultural understanding. Learners mentioned they came to the sense of progression in their cross-cultural learning. The students' comments reveal self-awareness of their emerging ability to identify cultural differences at the level of interaction. The content analyses of the interview data showed that the development of meta-pragmatic awareness allows learners not only to perceive cultural differences but to monitor their performance and to interpret the nature of cultural positioning in performance in English. The participants mentioned that analysis of situations brings them beyond a simplistic comparison of everyday routines. It reflects on constructing cultural concepts such as 'personal' and 'private' across cultures. They can identify linguistic differences stemming from culturally variable social constructs used to conceptualize and manage social relations. The learners understood that the negotiation of boundaries of appropriateness is one necessary aspect of interacting across cultures. Awareness of the cultural variability of the concepts became an important indicator of cultural assumptions.

\section{Discussion}

The study aimed to determine how to develop cultural knowledge and assumptions in the interpretation and evaluation of language use.

The content analysis of the results, based on six categories (narrative analysis, discourse analysis, semiotic analysis, interpretative analyses, conversation analysis, and critical analysis), showed the following results: the learners have become more reflective in interaction; they are consciously monitoring their cognitive and affective responses interactional activities conducted within the classroom. Learners started to consider the nature of their cross-cultural mediation.

The researchers defined the principles constituted a framework for cross-cultural teaching and learning: 1) teachers encourage learners to use both English and native language; 2) teachers promote the reflection on the experience of learners in English and native language; 3 ) teachers facilitate how learners explore both cognitive and affective dimensions of language use in discussion; 4) teachers help them to built abilities for reflecting on language use according to the context of interaction. The assumptions behind such principles were that engaging in 
reflection on aspects of pragmatics would necessitate a large amount of analysis in explicit discussion of interactional features and meaning concerning cultural context. This finding is consistent with that of McConachy (2018).

The results of this research support the findings of previous studies conducted by Linddicoat and Scarino (2013). They describe interpretative engagement in terms of noticing, reflecting, comparing, and interacting. Their research presents personal commentaries of L2 learners and shows how noticing, comparing, and interacting led learners to develop nuances of understanding of target language pragmatics. But their study does not show how an interpretative engagement might unfold in the classroom interaction.

The research of Van Compernolle (2004) pays attention to the construction of conceptual understanding of pragmatic features within student-teacher interaction. However, it does not adopt an intercultural perspective.

The study findings agree with the ideas of cross-cultural collaborative learning by KumiYeboah (2018), Chou \& Chen (2008). A cross-cultural collaborative framework motivates students to engage in learning, and supports them to make meaningful contributions in the construction of knowledge.

This study shows that the interpretative engagement of learners in a cross-cultural context can promote cross-cultural language learning in several ways. The performance of each learner constitutes a context to interpret by self and others. Learners can compare strategies for carrying out particular social acts and construct new meanings and reflections. It is different engagement with language from simply developing knowledge of L2 norms. It is a process of active construction within which learners' perceptions are in focus and become a resource for creating interaction strategies. Productive activities help learners to clarify understanding of their communicative intentions and choice of linguistic means. Linguistic choices are essential aspects of learning. They cultivate a view of language as a resource of communication. In the front of reflecting, students focus on the nature of context and interpersonal impressions they wish to construct in L2. Learners activate beliefs rooted in L1 cultural experience and then explore how to achieve their interactional and interpersonal goals through creative linguistic choices. Students mediate cultural norms, assumptions, and meta-pragmatic concepts. Learners thus creatively engage with language as a system of meanings. The cross-cultural mediation that accompanies this shift is driving the development of agency in L2.

\section{Conclusion}

The study aimed to investigate how the process of cross-cultural interaction shapes the learners' engagement in practices of context interpretation.

The research determined the design of the meaning-making process from multiple perspectives based on interpreting intentions, exploring constraints on speaker choices in interaction, scaffolding the construction of justifications for judgments, contextual modification for deepening reflective analysis. 
The results justified that the language teacher can create various opportunities for learners to reflect on and observe their performance in the classroom. They link students' capacities as 'performers' and 'analyzers' of language and culture and incorporate insights into their linguistic production. Scaffolding helps learners develop a perspective on language as a resource for language users. The study proved that through such an interpretative engagement, students become socialized into working with languages and cultures, which is essential for cross-cultural mediation.

\begin{abstract}
About the Authors
Anzhelika Solodka, Doctor of Science (Education), Professor of Department of German Philology and Translation at V.O. Sukhomlynskyi National University of Mykolaiv, Ukraine. Her main areas of interest include Cross-cultural Communication, Applied Linguistics and Translation. https://orcid.org/0000-0003-1703-7996
\end{abstract}

Oksana Filatova, Doctor if Philological Sciences, Professor of the Department of Social Studies and Humanities, Admiral Makarov National University of Shipbuilding, Mykolaiv, Ukraine. Her academic interest is in the field of philology and social communication. https://orcid.org/00000002-4464-6933

Oksana Hinkevych, Associate Professor of the Department of Social Studies and Humanities, Admiral Makarov National University of Shipbuilding, Mykolaiv, Ukraine. Her academic interest is in the field of philology, social communication, and higher education pedagogy. http://orcid.org/0000-0002-6008-28X

Oleksandr Spanatiy, Candidate of Sciences in Social Communications (PhD), Associate Professor of the Department of Department of Social Studies and Humanities, Admiral Makarov National University of Shipbuilding. His academic interest is in the field of social communication. https://orcid.org/0000-0003-1939-3900

\title{
References:
}

Baker, W. (2015). Culture and Identity through English as a Lingua Franca: Rethinking Concepts and Goals in Intercultural Communication. Berlin: Mouton de Gruyter.

Byram, M. (1997). Teaching and Assessing Intercultural Communicative Competence. Clevedon: Multilingual Matters.

Chou, P. N., \& Chen, H. H. (2008). Engagement in online collaborative learning: A case study using a Web 2.0 tool. Journal of Online Learning and Teaching, 4 (4), 574-582.

Cook, G. (2010). Translation in Language Teaching: An Argument for Reassessment. Oxford: Oxford University Press.

Crozet, C. (1996). Teaching verbal interaction and culture in a language classroom. Australian Review of Applied Linguistics (ARAL), 19 (2), 37-57. DOI: https://doi.org/10. 1075/aral 19.2.03cro

Diaz, A. R. \& Dasli, M. (2017). Tracing the 'critical' trajectory of language and intercultural communication pedagogy. In A. R.Diaz \& M. Dsali (eds) The Critical Turn in Language and International Communication Pedagogy (pp. 3-21). New York: Routledge. 
Donato, R. (1994). Collective scaffolding in second language learning. In J. P. Lantolf \& G. Appel (eds) Vygotskian Approach to Second Language Research (pp. 33-56). Norwood, NJ: Ablex.

Goodwin, C. \& Duranti, A. (1992). Rethinking context: An introduction. In A. Durandti \& C. Goodwin (eds) Rethinking Context: Language as an Interactive Phenomenon (pp.1-42). Cambridge: Cambridge University Press.

Haugh, M. (2010). Intercultural (im) politeness and the macro-micro issue. In A. Trosborg (ed.) Handbook of Pragmatics. Vol.7, Pragmatics across Language and Culture (pp.139-166). Berlin: Mouton de Gruyter.

Haugh, M. (2012). Conversational interaction. In K. Allan \& K. M. Jazczolt (eds) Cambridge Handbook of Pragmatics (pp. 251-274). Cambridge: Cambridge University Press.

Neuendorf, K.A. (2020). The Content Analysis Guidebook. Thousand Oaks, CA: SAGE.

Houghton, S. A. (2012). Intercultural dialogue in Practice: Managing Value Judgment through Foreign Language Education. Bristol: Multilingual Matters.

Ishihara, N. \& Cohen, A. D. (2010). Teaching and Learning Pragmatics: Where Language and Culture Meet. Longman Applied Linguistics.

Kasper G. \& Rose, K. R. (2001). Pragmatics in language teaching. In K. R. Rose and G. Kasper (eds) Pragmatics in Language Teaching (pp.1-9). Cambridge: Cambridge University Press.

Kearney, E. (2016). Intercultural Learning in Modern Language Education: Expanding Meaning-Making Potentials. Bristol: Multilingual Matters.

Kecskes, I. (2014). Intercultural Pragmatics. Oxford: Oxford University Press.

Kim, D. (2020). Learning Language, Learning Culture: Teaching Language to the Whole Student. Retrieved from https://journals.sagepub.com/doi/full/10.1177/2096531120936693

Kumi-Yeboah, A. (2018). Designing a cross-cultural collaborative online learning framework for online instructors. Online Learning, 22(4), 181-201. doi:10.24059/olj.v22i4.1520

Liddicoat, A. (2014). Pragmatics and Intercultural Mediation in Intercultural Language Learning. Intercultural Pragmatics, 11 (2), 259-277. DOI: http://dx.doi.org/10.1515/ip-2014-0011

Liddicoat, A. \& Scrino, A. (2013). Intercultural Language Teaching and Learning. New York: Wiley-Blackwell.

Lo Castro, V. (2003), An Introduction to Pragmatics: Social Action for Language Teachers. Ann Arbor, MI: University of Michigan Press.

McConachy, T. (2013). Exploring the meta-pragmatic realm in English language teaching. Language Awareness, 22 (2), 100-110. DOI: http://dx.doi.org/10.1080/096 58416. 2011. 644795

McConachy, T. (2018). Developing Intercultural Perspectives on Language Use. Exploring Pragmatic in Culture in Foreign Language Learning. Multilingual Matters. Bristol: Blue Ridge Summit.

McCornahy, T. \& Liddicoat, A. (2016). Meta-pragmatic awareness and intercultural competence: The role of reflection and interpretation in intercultural mediation. In F.Dervin and Z.Gross (eds) Intercultural Competence in Education: Alternative Approaches for Different Times (pp.13-30). London: Palgrave Macmillan.

Meier, A. J. (2015). The role of noticing in developing intercultural communicative competence. Eurasian Journal of Applied Linguistics, 1 (1), 25-38. Retrieved from https://doaj. org/article /a2876e8a05a042e490eabd2d42777ad1

Phipps, A. \& Gonzalez, M. (2005). Modern Languages: Learning and Teaching in an Intercultural Field. London: SAGE. 
Pizziconi, B. (2009). Stereotyping communicative styles in and out of the language classroom: Japanise indirectness, ambiguity, and vagueness. In R. Moron, M. Cruz, M. Amaya \& M. Lopez (eds) Pragmatics Applied to Language Teaching and Learning (pp.221-253). Cambridge: Cambridge Scholars.

Scarino, A. \& Liddicoat, A. (2016). Reconceptualizing learning in transdisciplinary language education. L2 Journal 8 (4), 20-35. DOI:10.5070/L28429918.

Solodka, A. (2015). Cross-cultural interaction of educational process participants in higher education. Mykolaiv: Illilon.

Solodka, A., \& Perea, L. (2018). The Speech Act of Complimenting as Part of the Ukrainian, Russian and English-Speaking Communities: Ukraine and the USA. Arab World English Journal, 9 (4), 39-55. DOI: https://dx.doi.org/10.24093/awej/vol9no4.3

Solodka, A., Perea, L. \& Romanchuk N. (2019). Interlanguage Development of English Complimenting Speech Acts: Strategies of Performance. Arab World English Journal, 10 (4), 18 -32. DOI: https://dx.doi.org/10.24093/awej/vol10no4.2

Solodka, A., Zaskaleta, S., Moroz, T., \& Demianenko, O. (2021). Sheltered Instructional Observational Protocol Model in Digital Teaching EFL Students in Ukraine. Arab World English Journal (AWEJ) Special Issue on Covid 19 Challenges (1) 21-36. DOI: https://dx.doi.org/10.24093/awej/covid.2

Swain, M. \& Lapkin, S. (2010). Talk-based second language learning: The uses of the first language. Language Teaching Research, 4 (3), 251-274. DOI: https://doi.org/10.1177/ 136216880000400304

van Compernolle, R.A. (2014). Sociocultural Theory and L2 Instructional Pragmatics. Bristol: Multilingual Matters.

Van Lier, L. (1996). Interaction in the Language Curriculum: Awareness, Autonomy, and Authenticity. Harlow: Longman.

Verbitskyi, A. (2004). Competitive approach and theory of context teaching. Moscow: Research center of education.

Vershueren, J. (2004). Notes on the role of meta-pragmatic awareness in language use. In A. Jaworski, N. Coupland \& D. Galasinski (eds) Metalanguage: Social and Ideological Perspectives (pp.53-73). Berlin: Mouton de Gruyter.

Zhukova, N. (2005). Contexts in the education of personality. Moscow: Moscow M. A. Sholokhov State University. 